\title{
The Structural Relationship Model of Indicators of Mindful Leadership for Primary School Principals
}

\author{
Sthian Wongkom ${ }^{1}$, Wirot Sanrattana ${ }^{2} \&$ Prayuth Chusorn $^{3}$ \\ 'Doctoral student in Educational Administration Program, Mahamakut Buddhist University, Northeastern Campus, \\ Thailand. \\ ${ }^{2}$ Thesis adviser in Doctoral Program of Educational Administration, Mahamakut Buddhist University, Northeastern \\ Campus, Thailand. \\ ${ }^{3}$ Thesis co-adviser in Doctoral Program of Educational Administration, Mahamakut Buddhist University, Northeastern \\ Campus, Thailand. \\ Correspondence: Wirot Sanrattana, Mahamakut Buddhist University, Northeastern Campus, Thailand. E-mail: \\ wirsan@kku.ac.th
}

Received: August 1, 2019

Accepted: August 21, 2019

Online Published: August 22, 2019

doi:10.5430/ijhe.v8n5p134

URL: https://doi.org/10.5430/ijhe.v8n5p134

\begin{abstract}
This study is a descriptive research study aiming to: 1) test the fitness between the theoretical model of the mindful leadership indicators and empirical data and 2) investigate factor loading value of the main elements, sub-elements, and indicators with models. The population of the research is 27,718 primary school principals under the office of the Basic Education Commission. Data collection means was rating-scale questionnaire from 610 participants in the sample group selected randomly by a multi-stage sampling technique. The data was analysed using a computer program. The results of the research confirmed the hypotheses of the research which are: the theoretical model is relevant to the empirical data, and the value of Relative Chi-Square (CMIN/DF), Root Mean Square Error of Approximation (RMSEA), Goodness-of-Fit Index (GFI), Adjusted Goodness-of-Fit Index (AGFI), Comparative Fit Index (CFI), and (6) Normed Fit Index (NFI) is in accordance with the criteria and 2) the value of factor loading of the main elements is between $0.84-1.70$ which is 0.70 higher than the criteria, the value of factor loading of the sub-elements is between $0.31-1.95$, and the value of the factor loading of the indicators is between $0.30-8.26$ which is 0.30 higher than the criteria.
\end{abstract}

Keywords: indicator, mindful leadership, primary school principals

\section{Introduction}

Most people's mental state will normally involve only conscious and unconscious (sleeping) states. However, generally there is a higher mental state when the body is conscious (not sleeping) but the mind is calm and peaceful. This higher state generates special brain waves which are clearly different from when we are awake, asleep, and dreaming. This higher state of mind was proved to be enhanced by meditation. When a person meditates, he or she will be able to live their lives happily without misery; it also helps recover from physical diseases and mental disorders and effectively solve problems. When mindfulness and meditation are applied in daily routine, work, life, family, and social interaction will benefit drastically (Wisalo, 2014).

In the case of mindfulness, Kabat-Zinn (2003) who is a professor in medicine at a medical university in Massachusetts and also the master of mindfulness of the West - an initiator of Mindfulness-Based Stress Reduction Program stated that mindfulness means being conscious and aware of oneself every moment - thoughts, emotions, and feelings - both physical and environmental. Mindfulness also includes acceptance meaning that a person is focusing on the thoughts and feelings without judging at that moment. While meditating, our thoughts will be adjusted with the feeling at the moment without being obsessed or worried about the future.

Meditation - The Free Dictionary by Farlex (2014) defined meditation as a practice to focus on a sound, an object, a picture in mind, breath, movement, or one's attention in order to increase consciousness of the present moment, help reduce stress and relax more, and result in the growth of individual and spirit. It is a persistence of the mind to rest from all thoughts because generally, there are always thoughts in the mind. When unsatisfactory thoughts are collected, the mind will be distraught and stressed. 
This research focused on the study about mindfulness, and according to Brown and Ryan (2003) and Kabat-zinn (2003)'s concepts about mindfulness, the basic concept about mindfulness is from Buddhism which is similar to the study of intelligence of human. Zohar (2000); Emmons (2000); Wolman (2001); Amram (2007); and King (2008) mentioned various types of human intelligence, especially spiritual intelligence or SQ which refers to one's ability to think critically and analyse life and situations in one's life which then results in self-understanding - knowing and understanding the real meaning of one's life, being able to truly know the purpose of one's birth and life as well as understand the relationships between oneself and others, see the connection of things, and being able to change one's attitude and deal with problems in life when facing them.

When considering the viewpoint of spiritual intelligence as previously mentioned, the definition of it is likely to be more similar to the viewpoint of Buddhist intelligence rather than intelligence in terms of psychology. That is, spiritual intelligence is a part of Buddhist intelligence in the aspect of one's logical way of thinking which means knowing one's strengths and weakness or desires and how these things can darken the mind and being able to handle one's desires by applying the Buddha's teaching as one learns as a discipline, being able to adjust one's point of view, and being able to handle the misery in one's life.

When considering the viewpoint of spiritual intelligence and its connection to mindful leadership--which some academics such as Wisalo (2014) called the state of leading with mindfulness--mindfulness means to apply meditation in daily routine and work until it becomes a conscious way of life in terms of one's actions, interactions with other people, and emotions. The pattern of meditation which Thai people are familiar with is sitting meditation; meditation can be done in different patterns such as being aware of oneself when doing things - seeing and abandoning emotions that are occurring.

Even though meditation is something that Thai people are familiar with because it is one of the key elements of Buddhism, the concept of mindful leadership was developed as a part of the management theory of Western academics. They believed that if a leader possesses the qualities acquired from meditating such as clearer thinking, being more aware of self-emotions, long vision, and being determined for one's goals, there will be a positive result for the organization. Meditation helps us to see more clearly what is important to us and makes us understand more about the world around us. Meditation helps increase the possibility of seeing the importance of smaller things and mind the possibility of being anxious about unimportant things. It generates energy to work, helps us be kind and generous to other people, and helps us encourage colleagues in the organisation. Therefore, the goal of mindful leadership according to the Western academics' points of view is different from Buddhism's meditation. In Buddhism, the goal of meditation is salvation, as Thai people are familiar with, but for the Western academics, meditation is used in management, individual's potential development, and organisation development (George, 2010; Myers, 2015).

In this research, the aim is to study mindful leadership according to the Western academics' points of view which is applied as a tool for management, individuals potential development, and organizational development because it is seen as a concept that can be used to develop school principals in today's society. From the literature review, the academics mentioned the components of mindful leadership. For example, Riddle (2012) mentioned three components which are: 1) an empty mind, 2) non-reactivity, and 3) permissive attention. Hawkins (2011) discussed four components which are: 1) makes the implicit explicit while increasing mindfulness of, and lessening attachments to, things, thoughts, emotions, and other objects; 2) engages the collective in understanding where they are and where they might be; 3) forges understanding and movement out of many voices, and 4) uses a holistic process that enables others to determine how they fit and what they owe the world based on what is emerging. Lamos (2014) talked about five components which are: 1) authentic leadership and genuine intentions, 2) mindful leaders actively develop mindfulness, 3) mindful leaders are aware of their impact, 4) being mindful improves creativity, innovative thinking and a sharp assessment of the current reality, and 5) acceptance of the situation as it is, improves sound decision-making. Oetting (2015) discussed six components: 1) accountable, 2) value clarity, not speed, in decision-making, 3) adaptive, 4) start with compassion, 5) open to change and innovation, and 6) prevent burnout -- in themselves and their team. Williams (2016) mentioned seven components which are: 1) consciously focusing on the present, 2) introspective self-awareness, 3) energy management, 4) intentionally responding, rather than unconsciously reacting, 5) demonstrating acceptance and compassion, 6) openness, and 7) non-attachment. Ataya (2012) talked about nine components: 1) be present, 2) be aware, 3) be calm, 4) be focused, 5) be clear, 6) be equanimous, 7) be positive, 8) be compassionate, and 9) be impeccable. Finally, Inam (2012) mentioned 10 elements which are: 1) stress reduction, 2) self-awareness, 3) greater empathy for self, 4) manage our energy, 5) become a better listener, 6) strongly engage others, 7) creating distance between thought and action, 8) tap into intuition, 9) embrace and adapt to change, and 10) greater clarity and focus. 
Furthermore, there are academics who mentioned the components of mindful leadership in many different points of view - both similar to and different from each other. We think that if we were to synthesize those components and synthesize them using high frequency criteria in order to create a theoretical model and test it in the context of Thai society, there will be an acquisition of new knowledge about the components of mindful leadership which will be able to apply in Thai society's context with research guarantee. Thus, we firmly decided to study theories from 17 sources, and after synthesizing, it was found that the components which the academics agreed as the keys of mindful leadership with high frequency are: Self-Awareness (SEA), Commitment (CMT), Compassion (CPS), and Good Decision (GDC). From more review of the literature, it was also found that each key component comprised of sub-components as follows: self-awareness (SEA) comprises of emotional awareness (SEA1), self-assessment (SEA2), and self-limitation (SEA3); Commitment (CMT) comprises of goal (CMT1), positive attitude (CMT2), loyalty to work (CMT3), and enthusiasm (CMT4); Compassion (CPS) comprises of kindness (CPS1), generosity (CPS2), merciful (CPS3), and conscious (CPS4); and Good Decision (GDC) comprises of purpose (GDC1), organize ideas (GDC2), and aware of biases (GDC3).

From these findings, we have built a structural relationship model of the mindful leadership indicators; this is considered a theoretical model and also a hypothesis model for the research as shown in Figure 1:

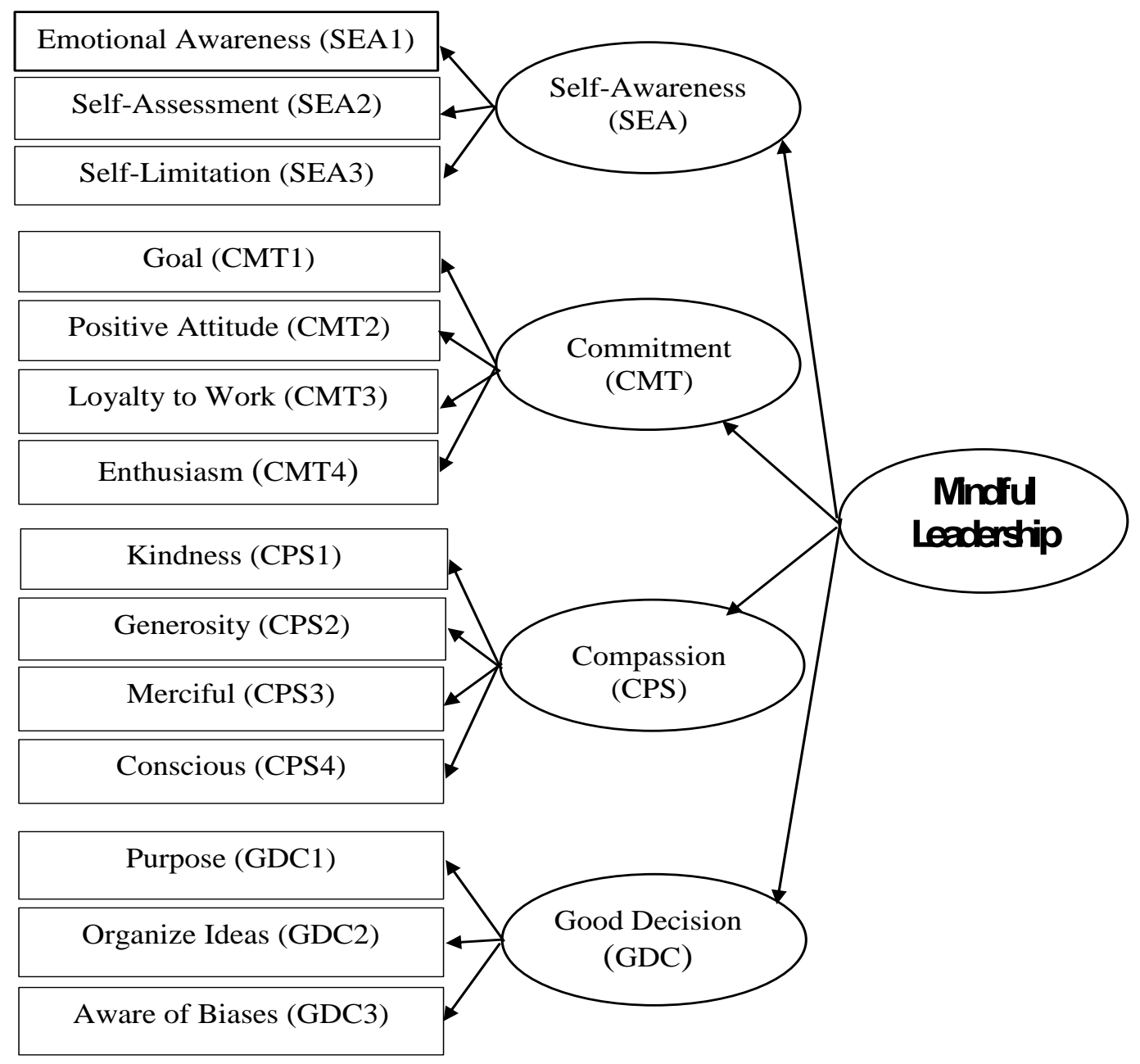

Figure 1. Structural Relationship Model of the Indicators of Mindful Leadership: Theoretical Model and Hypothesis Model for Research

From the model in Figure 1, we continuously studied the related theories to determine the indicators of each sub-component and finally came up with 60 indicators (not discussed in this chapter because of the number). This is a theoretical model of mindful leadership which shows the structural relationship of the four key components, 14 sub-components and 60 indicators which can be applied for the research. The research questions, research hypothesis and research methodology will be discussed later. 


\section{Research Question}

Are the theoretical models of mindful leadership which shows the structural relationship between four key components, 16 sub-components and 60 indicators which were developed from the theories and the empirical data relevant? Is the value of factor loading of the key components, sub-elements and the indicators in accordance with the set criteria?

\section{Research Hypothesis}

To answer the research questions as mentioned previously, we have set the research hypothesis to predict the answers as follows:

3.1) The theoretical model of mindful leadership is relevant to the empirical data in accordance with the criteria set by Hair, Black, Babin, \& Anderson (2010) which are (1) Relative Chi-Square (CMIN/DF) is less than 3.00, (2) Root Mean Square Error of Approximation (RMSEA) is lower than 0.05, (3) Goodness-of-Fit Index (GFI), (4) Adjusted Goodness- of - Fit Index (AGFI) (5) Comparative Fit Index (CFI), and (6) Normed Fit Index (NFI) is between 0.90 - 1.00.

3.2) The key components of the theoretical model of mindful leadership have factor loading equal to or higher than 0.70 (Farrell \& Rudd, 2009); the sub-components and the indicators have factor loading equal to or higher than 0.30 (Tacq, 1997).

\section{Research Methodology}

According to Wiratchai (2002)'s point of view, there are three procedures for the educational indicators development: 1) Pragmatic Definition - the researcher uses self-experiences to select the variables to present the model, 2) Theoretical Definition - the researcher applies theories and research to create a model and present it for immediate application or ask the experts to investigate the model before used, 3) Empirical Definition - the researcher uses theories to create a model then test it with the empirical data; if relevant after Confirmative Factor Analysis, it can later be used to benefit the management, the individual's potential development and the organization's development.

For this research, we used the empirical definition of the indicators development which, according to Sanrattana (2018), is more of a scientific procedure for the usage of the empirical data collected from the sample group which was randomly selected from the population to judge the structural accuracy; thus, there is no weakness related to bias from personal feelings and experiences of the researcher or the experts. The research methodology is as follows:

\subsection{Population and Sample}

Due to the primary school under the Office of Basic Education Commission is a public school with a population spread throughout the country. The results of the research will be able to be used to develop mindful leadership to occur with those populations widely. So, the population of this research is 27,718 public primary school principals under the Office of Basic Education Commission in academic year 2018. (Office of the Basic Education Commission Department Operation Center, 2018) The determination of the sample size was from the application of 20:1 proportion rule between sample unit to number of parameters by counting the parameters from five latent variables, 17 observed variables and 18 influence lines - 37 parameters in total. There are 740 participants in the sample group of the research.

\subsection{Instrument}

The research instrument was a questionnaire divided into two parts: 1) questions about the status of the informants in a form of a checklist, and 2) questions related to behaviours or expressions showing mindful leadership in a form of rating scale criterion. The second part of the questionnaire was categorized in accordance with the key and sub-components; it consisted of 60 questions, and this research instrument was created and developed by ourselves through the work process: 1) to study the theories to set the key components, (2) to study the theories to set the sub-components of each key component, (3) to study the theories to set the indicators of each sub-component, (4) to make questions from the indicators and an investigation form to test the relevance between the questions and the indicators, and then ask six experts in the educational administration field to confirm the relevance, (5) to carry out a try-out for the questionnaire with 30 randomly selected school principals then analyze the collected data to find Alpha coefficient of reliability by Cronbach. The result of the data analysis is that the Alpha coefficient of reliability of the whole questionnaire equals 0.976 . When categorizing each key element, it was found that Self-Awareness (SEA) equals .904; Commitment (CMT) equals .956; Compassion (CPS) equals 0.944, and Good Decision (GDC) equals 0.945. This shows that the Alpha coefficient of reliability is higher than the set value in the criterion at the level of 0.70 (Prasertratasin, 2003). 


\subsection{Data Collection}

The population of the primary school principals around the country consists of 27,718 people, and we applied multistage random sampling to select participants; there were 740 participants in the sample group. Afterward, the questionnaires were sent to the participants by post. After 5 months of follow-up, 610 questionnaires were returned from the sample group which is $82.43 \%$ of the total sent questionnaires. After considering Kaiser-Meyer-Olkin (KMO) test for sampling adequacy of the returned questionnaires, it was found that the value was between .904 -.933 showing that the number of the questionnaires was sufficient for the research.

\subsection{Data Analysis}

The data was analyzed by a computer program to find essential statistic values: 1) Pearson's correlation coefficient and Bartlett's statistic values to consider the suitability of the variables in order to be analyzed for confirmatory components, 2) KMO (Kaiser-Meyer-Olkin (KMO) test for sampling adequacy in order to consider the sufficiency of the questionnaires for the research, and 3 ) the first order of confirmatory factor analysis and the second order of confirmatory factor analysis to test the fitness of the theoretical model with the empirical data.

\section{Research Results}

\subsection{The Results of the Fitness Test of the Theoretical Model and the Empirical Data}

The results of the first order of confirmatory factor analysis to test the fitness of the theoretical model of the key components which are: Self-Awareness (SEA), Commitment (CMT), Compassion (CPS), and Good Decision (GDC), found that there is fitness between the empirical data with every model by considering statistic values which could be analyzed by comparing the data with the set criterion as shown in Table 1:

Table 1. The Results of the First Order of Confirmatory Factor Analysis to Test the Fitness of the Four Theoretical Models with the Empirical Data Comparing to the Set Criterion

\begin{tabular}{|c|c|c|c|c|c|c|}
\hline Measurement Model / Criteria & $\begin{array}{l}C M I N \\
<3.00\end{array}$ & $\begin{array}{c}\text { RMSEA } \\
<0.05\end{array}$ & $\begin{array}{c}G F I \\
0.90-1.00\end{array}$ & $\begin{array}{c}A G F I \\
0.90-1.00\end{array}$ & $\begin{array}{c}C F I \\
0.90-1.00\end{array}$ & $\begin{array}{c}N F I \\
0.90-1.00\end{array}$ \\
\hline $\begin{array}{c}\text { Self-Awareness (SEA) } \\
\text { - Emotional Awareness (SEA1) } \\
\text { - Self - Assessment (SEA2) } \\
\text { - Self - Limitation (SEA3) }\end{array}$ & 1.797 & 0.036 & 0.984 & 0.963 & 0.992 & 0.982 \\
\hline $\begin{array}{c}\text { Commitment (CMT) } \\
\text { - Goal (CMT1) } \\
\text { - Positive Attitude (CMT2) } \\
\text { - Loyalty to Work (CMT3) } \\
\text { - Enthusiasm (CMT4) }\end{array}$ & 1.909 & 0.039 & 0.971 & 0.937 & 0.991 & 0.981 \\
\hline $\begin{array}{l}\text { Compassion (CPS) } \\
\text { - Kindness (CPS1) } \\
\text { - Generosity (CPS2) } \\
\text { - Merciful (CPS3) } \\
\text { - Conscious (CPS4) }\end{array}$ & 2.452 & 0.049 & 0.973 & 0.937 & 0.979 & 0.966 \\
\hline $\begin{array}{c}\text { Good Decision (GDC) } \\
\text { - Purpose (GDC1) } \\
\text { - Organize ideas (GDC2) } \\
\text { - Aware of Biases (GDC3) }\end{array}$ & 2.430 & 0.048 & 0.984 & 0.951 & 0.982 & 0.978 \\
\hline
\end{tabular}

The results of the research confirmed that Self-Awareness (SEA), Commitment (CMT), Compassion (CPS), and Good Decision (GDC) are the key components of Mindful Leadership (MFD) by showing 12 sub-component scales as follows: 
Self-Awareness (SEA)

SEA1 $=($ SA1 + SA2 + SA3 + SA4 $)=(0.05+0.11+0.15+0.23)=0.54$
SEA2 $=($ SA5 + SA6 + SA7 + SA 8$)=(0.21-0.17+0.11+0.25)=0.74$
SEA3 $=($ SA9 + SA10 + SA1 $1+$ SA12 $)=(0.18+0.13+0.12-0.16)=0.59$

Commitment (CMT)

$\mathrm{CMT} 1=(\mathrm{CM} 13+\mathrm{CM} 14+\mathrm{CM} 15+\mathrm{CM} 16)=(0.01+0.01+0.10+0.10)=0.22$

$\mathrm{CMT} 2=(\mathrm{CM} 17+\mathrm{CM} 18+\mathrm{CM} 19+\mathrm{CM} 20+\mathrm{CM} 21)=(0.05-0.06+0.05+0.05+0.05)=0.21$

$\mathrm{CMT} 3=(\mathrm{CM} 22+\mathrm{CM} 23+\mathrm{CM} 24+\mathrm{CM} 25+\mathrm{CM} 26+\mathrm{CM} 27)=(0.24+0.09+0.04-0.03+0.15+0.10)=0.60$

$\mathrm{CMT} 4=(\mathrm{CM} 28+\mathrm{CM} 29+\mathrm{CM} 30+\mathrm{CM} 31+\mathrm{CM} 32)=(0.22+0.26+0.19+0.14+0.18)=0.89$

Compassion (CPS)

$\mathrm{CPS} 1=(\mathrm{CP} 33+\mathrm{CP} 34+\mathrm{CP} 35+\mathrm{CP} 36)=(0.07+0.08+0.15+0.18)=0.48$

$\mathrm{CPS} 2=(\mathrm{CP} 37+\mathrm{CP} 38+\mathrm{CP} 39+\mathrm{CP} 40)=(0.22-0.02+0.15+0.20)=0.55$

$\mathrm{CPS} 3=(\mathrm{CP} 41+\mathrm{CP} 42+\mathrm{CP} 43+\mathrm{CP} 44)=(0.13+0.12+0.11-0.16+0.06)=0.58$

$\mathrm{CPS} 4=(\mathrm{CP} 45+\mathrm{CP} 46+\mathrm{CP} 47+\mathrm{CP} 48)=(0.13+0.12+0.11-0.16+0.06)=0.58$

Good Decision (GDC)

GDC1 $=($ GD49 + GD50 + GD51 $)=(0.06+0.02+0.09)=0.17$

GDC2 $=($ GD52 + GD53 + GD54 + GD55 + GD56 $)=(0.05-0.23+0.15+0.71+0.16)=1.82$

GDC3 $=($ GD57 + GD58 + GD59 + GD60 $)=(0.05+0.14+0.05-0.12)=1.79$

From 12 scales of the sub-components, we set the Measurement Model of Mindful Leadership (MFD) to test the fitness of the model with the empirical data again, and after the second order of confirmatory factor analysis, it was found that the measurement model of mindful leadership (MFD) which is the theoretical model is fit to the empirical data by considering statistic values which were analyzed comparing to the set criterion as shown in Table 2:

Table 2. The Results of the Second Order of Confirmatory Factor Analysis to Test the Fitness of the Theoretical Model of Mindful Leadership (MFD) with the Empirical Data Compared with the Set Criterion

\begin{tabular}{ccccccc}
\hline Measurement Model /Criteria & CMIN & RMSEA & GFI & AGFI & CFI & NFI \\
& $<3.00$ & $<0.05$ & $\mathbf{0 . 9 0 - 1 . 0 0}$ & $\mathbf{0 . 9 0 - 1 . 0 0}$ & $\mathbf{0 . 9 0 - 1 . 0 0}$ & $\mathbf{0 . 9 0 - 1 . 0 0}$ \\
\hline Mindful Leaders (MFD) & 2.463 & 0.049 & 0.965 & 0.941 & 0.942 & 0.908 \\
- Self-Awareness (SEA) & & & & & & \\
- Commitment (CMT) & & & & & & \\
- Compassion (CPS) & & & & & & \\
- Good Decision (GDC) & & & & & & \\
\hline
\end{tabular}

Moreover, we also investigated factor loading values of the four key components, which are Self-Awareness (SEA), Commitment (CMT), Compassion (CPS), and Good Decision (GDC) and found that the factor loading values are positive and statistically significant at the level of 0.01 . Each key component's factor loading value is as follows: 1) Self-Awareness $(\mathrm{SEA})=0.84,2)$ Commitment $(\mathrm{CMT})=1.70,3)$ Compassion $(\mathrm{CPS})=1.59$, and 4) Good Decision $(\mathrm{GDC})$ $=1.00$.

From previous factor loading values, we used those numbers to create a scale of the mindful leadership (MFD) components which can be shown as an equation: $\mathrm{MFD}=1.70(\mathrm{CMT})+1.59(\mathrm{CPS})+1.00(\mathrm{GDC})+0.84$ (SEA).

5.2 The Results of the Investigation of Factor Loading Values of the Components

The results of the research are: 1) Key component level - factor loading values of the four key components are positive and statistically significant at level of .01. The component called self-awareness (SEA)'s factor loading value is the lowest which is 0.84 but still 0.70 higher than the set criterion. Factor loading values of the 14 sub-components are positive and statistically significant at level of .01 as well, 2) Sub-component level - factor loading values of 14 sub-components are positive and statistically significant at level of .01. The sub-component called Communication's factor loading value is the lowest which is 0.72 but still 0.30 higher than the set criterion, and 3) Indicator level - factor 
loading values of 60 indicators are positive and statistically significant at level of .01 . The indicator called systematic management's factor loading value is the lowest which is 0.30 and equals the set criterion as well.

When considering the factor loading values in different levels which are higher than the set criteria, the theoretical models of mindful leadership (MFD) showed that the structural relationships of the four key components, 14 sub-components, and 60 indicators have construct validity, and thus are able to be used as a guideline in the development of the primary school principals under the Office of the Basic Education Commission in Thailand with research guarantee.

\section{Discussion and Recommendations}

As the results of the theoretical models of mindful leadership's fitness with the empirical data according to the set criteria show, there are reasons that the researchers discuss two aspects as in the studies of Marwieang, Sanrattana \& Suwannoi (2018) and Somsueb, Phrakrusutheejariyawat \& Suwannoi (2018) as follows: first aspect - from the point of view of the theories used to create the models that fit with the empirical data, it shows that the theories are relevant to mindful leadership behaviours of the sample group in the research. This could be the theories' universality - wherever the theories might be from, they will spread around the world following the trend of globalization. According to Eaoapitorn (2018)'s point of view about globalization, it makes the line between countries thinner than ever before; people are able to travel from one country to another more easily. Additionally, according to Crouhecr (2004), globalization is a melting pot, turning the world population into one society. This process occurs as a result of economic, technological, social-cultural, and political co-influences. Moreover, according to Luangmeekul (2014), globalization is a process of global social change covering enormous changes which affect all aspects of the way of life of the world population- economically, socially, politically and governmentally, legally, technologically, and culturally; second aspect - in terms of the sample group of the research, it is possible that school principals have developed themselves to follow the trend of changes - both from their consciousness and from the policies and practical guidelines from the organisations. As school principals have many responsibilities, to succeed in the administration requires many factors especially self-development as there are always changes in society, regions, and world society especially the society of learning in a technological era in which people can access information from all regions around the globe. As Weigel (2012) said, school principals must be supported to develop their skills, knowledge and experiences at work to prepare for the competition in context of World's new era. This also corresponds with Lee (2008) who found that to succeed at work school principals need to develop themselves to build leadership skills to build strong relationships with other people. Ejimofor (2007)'s study also found that the development of leadership skills of school principals is essential because necessary knowledge about being a successful leader will be acquired; they later understand and behave appropriately for administration and impress their team. The study of National Association of Secondary School Principals (NASSP) (2019) found that in the $21^{\text {st }}$ century, school principals need to adjust and develop themselves in order to follow new changes happening.

The findings of factor loading values of the key components, sub-components and the indicators of the theoretical models of mindful leadership showed that they were as the set criteria: the factor loading values of the key components is equal to or are higher than 0.70 , and the factor loading values of the sub-components and indicators are equal to or higher than 0.30 . The researcher has studied from many sources and synthesized to select the key components, sub-components, and the indicators used in this research. They are then put in the models by considering the validity of the content or the variables studied in every procedure - the procedure to determine the key and sub-components and the study of practical definitions to determine the indicators. It shows that the theoretical models of mindful leadership can be applied in the development of mindful leadership for primary school principals under the Office of the Basic Education Commission with research guarantee.

In the case of staff development, the coverage of the four key components should be taken into account as well as the 13 sub-components and the factor loading values - from high to low, as shown as an administration conceptual framework for the development of mindful leadership for primary school principals under the Office of the Basic Education Commission in Thailand in Figure 2 (ranking the importance according to the factor loading values from high - low for both key and sub-components). 


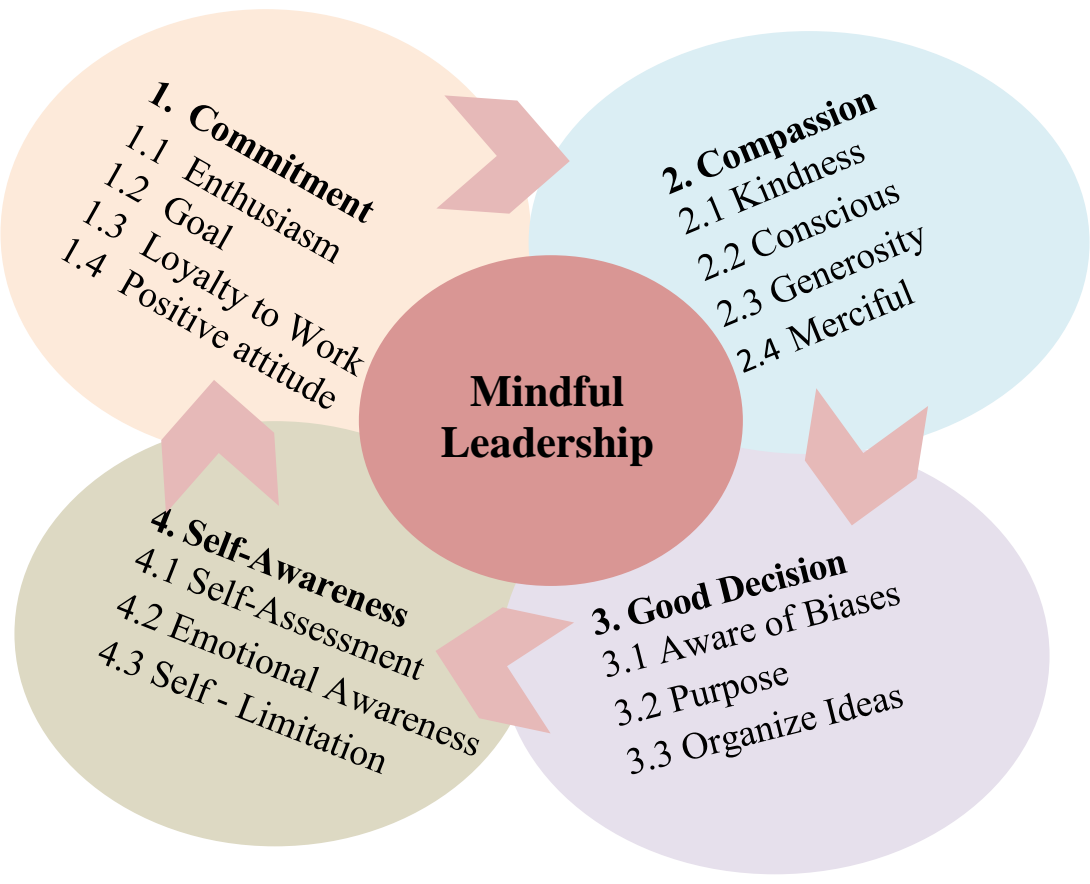

Figure 2. Administration Conceptual Framework for Mindful Leadership Development for Primary School Principals under the Office of the Basic Education Commission in Thailand (The figure was developed by the researchers)

However, the use of this research's results for further research or for the staff development should take into account that the key elements of this study were the result of 17 references; there are 34 theoretical key elements, but four were selected for this study due to their higher frequency. Even though some of the other 30 left elements were lower in frequency, they are worthy of researching. Examples include: continuing consciousness, positive force, staying present, emotional intelligence, lifebuoy, love mercy, modesty, staying focused, listening, paying attention to yourself, being careful, understanding the situation, having responsibility, good adaptability, creativity, holistic process, the need to reduce, agreeing with the participation, distance between thinking and doing, , having a good time, cultivating, uncleanliness one's influence on society, having courage, having patience, accepting failure, developing, innovating, preventing boredom, new generation leader, responding more than silence, having an open mind and not vulgar. Therefore, we suggest the researchers who are interested in the development of the mindful leadership indicators including the organisations that want to develop mindful leadership for their staff consider selecting those elements to use in the research or staff development as well.

\section{References}

Amram, Y. (2007). What is spiritual intelligence? An ecumenical, grounded theory. Retrieved January 19, 2016, from https://bit.ly/2GyIaAc

Ataya, M. (2012). Mindfulness and leadership. Retrieved January 18, 2016, from https://bit.ly/2LGZuaE

Brown, K. W. \& Ryan, R. M. (2003). The benefits of being present: Mindfulness and its role in psychological well-being. Journal of Personality and Social Psychology, 84(4), 822-848.

Croucher S.L. (2004). Globalization and belonging: The Politics of identity in a changing world. New York: Rowman \& Littlefield.

Eaoapitorn, T. (2018). How do humans create skills - new learning to cope with future changes?. Retrieved January 7 , 2019, from https://bit.ly/2LSI1Ju

Ejimofor, F.O (2007). Principals' transformational leadership skills and their teachers job satisfaction in Nigeria. Dissertation Ph.D. Thesis in Philosophy Cleveland State University: Nigeria.

Emmons, R. (2009). Is spirituality an intelligence? Motivation, cognition and the psychology of the ultimate concern. Retrieved February 4, 2016, from https://bit.ly/2LMdOhO 
Farrell, A. M. \& Rudd, J. M. (2009). Factor analysis and discriminant validity: A Brief review of some practical issues. Retrieved September 21, 2019, from https://bit.ly/2HiPXm3

George, B. (2010). Mindful leadership: Compassion, contemplation and meditation develop effective leaders. Retrieved January 18, 2016, from https://bit.ly/1hEE22h

Hair, J.F., Black, W.C., Babin, B.J., and Anderson, R.E. (2010). Multivariate data analysis. (7th ed.). Upper Saddle River, NJ: Prentice Hall.

Hawkins, R. (2011). Feature article: Mindfulness matters. Retrieved June 18, 2011, from https://bit.ly/2MdE1p5

Inam, H. (2012). Breathe. meditate. lead. ten ways mindfulness practice can make us better leaders. Retrieved June 30 , 2011, from https://bit.ly/2Y2x55t

Kabat-Zinn, J. (2003). Mindfulness-based interventions in context: Past, present, and future. Retrieved July 12, 2017 , from https://bit.ly/2VfvzYe

King, D. B. (2008). Rethinking claims of spiritual intelligence: A Definition, model, and measure. Unpublished Ph.D. Thesis, Trent University Peterborough, Ontario, Canada.

Lamos, M. (2014). Five characteristics of mindful leadership. Retrieved January 18, 2016 from, https://bit.ly/2LoyicX

Lee, D. (2008). Randomized experiments from non-random selection in U.S. house elections. Retrieved February 28,2018 , from https://www.princeton.edu/ davidlee/wp/RDrand.pdf

Luangmeekul, P. (2014). Globalization. Retrieved December 21, 2018, from https://bit.ly/2QuF0zI

Marwieang, K., Sanrattana, W. \& Suwannoi, P. (2018). Indicators of resourceful leadership for secondary school principals: Developing and testing the structural relationship model. International Education Studies. Vol. 11 No. 11, November 2018, and Online published in October 2018.

Myers, M. (2015). Improving military resilience through mindfulness training. Retrieved March 15, 2017, from https://bit.ly/2Nzm5CG

National Association of Secondary School Principals (NASSP) (2019). 2013 Digital principals of the year. Retrieved March 15, 2019 from, https://bit.ly/2Zd81VE

Office of the Basic Education Commission Department Operation Center. (2018). Educational information. Retrieved May 12, 2018 from https://www.bopp-obec.info/home/

Prasertratasin, S. (2003). Research methodology in social science. (12th ed.). Bangkok: Puengfa Printing Co.

Riddle, D. (2012). Three keys to mindful leadership coaching. Retrieved January 18, 2016 from, https://bit.ly/2Lomh7g

Sanrattana, W. (2018). Research in educational administration: Concepts, guidelines, and case studies. (4th ed.). Bangkok: Tipwisut.

Somsueb, A., Phrakrusutheejariyawat \& Suwannoi, P. (2018). Indicators of innovative leadership for secondary school principals: developing and testing the structural relationship model. International Education Studies. Vol. 12 No. 1 January, 2018, and Online published in December 2018.

Tacq, J. (1997). Multivariate analysis techniques in social science research: From problem to analysis. London: SAGE Publications Ltd.

The Free Dictionary by Farlex (2014). Meditation. Retrieved March 23, 2017, from https://bit.ly/2GteQLp

Weigel, R. (2012). School leadership skill development. Retrieved January 23, 2018, from https://commons.emich.edu/theses/447/

Williams (2016). The 7 habits of highly mindful leaders. Retrieved February 8, 2017, from https://bit.ly/2NW4GW0

Wiratchai, N. (2002). Development of indicators for assessment of administration and management of Educational Service Areas. Bangkok: Thanaksorn.

Wisalo, P. (2014). "Consciousness" that is overlooked. Retrieved December 21, 2018, from https://bit.ly/31QZ8TH

Wolman, R. (2001). Thinking with your soul: Spiritual intelligence and why it matter. Retrieved January 15, 2016, from https://bit.ly/32 VoEYa

Zohar, D. (2000). SQ: Spiritual intelligence, the ultimate intelligence. Retrieved January 14, 2016, from https://bit.ly/2Y9xS4C 